\title{
The Effect of Changes in Regulation and Technology on Capital Investments
}

\author{
Vivian 0. Okere, Wen Chen \\ Department of Finance, Providence College, Providence, Rhode Island \\ Email: vokere@providence.edu,wchen@providence.edu
}

How to cite this paper: Okere, V.O. and Chen, W. (2021) The Effect of Changes in Regulation and Technology on Capital Investments. Journal of Mathematical Finance, 11, 331-359.

https://doi.org/10.4236/jmf.2021.112019

Received: February 6, 2021

Accepted: May 28, 2021

Published: May 31, 2021

Copyright (อ 2021 by author(s) and Scientific Research Publishing Inc. This work is licensed under the Creative Commons Attribution International License (CC BY 4.0).

http://creativecommons.org/licenses/by/4.0/

\begin{abstract}
Uncertainties in regulation could affect the decision to invest in irreversible capital projects. We use the geometric Brownian motion to analyze the effect of a stochastic carbon tax on the cash flows expected from investments and the value of the investments. Successful legislation on carbon tax may trigger changes in technology. Our results show that carbon tax accompanied by the adoption of a new technology could affect the value of an irreversible investment. Also the decision to invest depends on whether the cash flows exceed a pre-determined critical cash flow.
\end{abstract}

\section{Keywords}

Capital Investments, Real Option, Carbon Tax, Technology, Discount Rate, Stochastic Cash Flows

\section{Introduction}

There is a growing body of economic research on real option-based models on investment decisions under uncertainty and irreversibility [1] [2] [3] [4]. Investment decisions could be uncertain due to rapidly changing conditions in the global economy. In this research paper, we analyze how uncertainties in carbon taxation and the expected changes in technology could impact the decision to invest in irreversible capital investments.

Following Alm (1988) [5], an uncertain tax policy would increase the riskiness of an investment and ignoring uncertainty in carbon taxation on irreversible investments could lead to inappropriate investment decisions. Carbon tax is the tax levied on carbon present in hydrocarbon fuel such as petroleum, natural gas and coal. When hydrocarbon fuels are burnt, carbon dioxide $\left(\mathrm{CO}_{2}\right)$ is emitted in contrast to the non-combustion energy sources: wind, sunlight, hydropower and nuclear (see Yohe et al. 2007) [6]. This paper posits that a carbon tax on hydro- 
carbon fuels could be the theoretically ideal regulatory instrument for the abatement of carbon dioxide emissions and we argue that substitution effects between different sources of energy could be realized through innovation in technology. We extend the results of Dixit and Pindyck (1994) [7] and show that the imposition of carbon tax could delay or postpone the implementation of an investment even when the investment cash flows $\pi$ are greater than its critical value, $\pi^{*}$; that is $\pi>\pi^{*}$. Further, we also show using a technology threshold model, $K(t) \equiv K$ that the value of an investment could decrease in time in spite of the adoption of a new technology because investors prefer a higher rate of increase in cash flows at the early stages of the lifecycle of the investment. Therefore, we analyze how the expected cash flows of an irreversible investment could be affected if the investment warrants the imposition of carbon tax and simultaneously analyze how the adoption of a new technology could affect the value of the irreversible investment.

\section{Background and Literature Review}

Niemann 2011 [2] and Niemann and Sureth, 2005 [3], most environmentally related taxes in the Organization of Economic Co-operation and Development (OECD) countries are levied on energy products and motor vehicles rather than on $\mathrm{CO}_{2}$ emissions. As such, the economic impact of carbon tax is a well-researched topic internationally.

There is increased attention to green products because they are environmentally friendly and as a result, a number of firms are investing in green products. For instance, PepsiCo and Coca Cola have developed recyclable PET plastic soft drink bottles instead of corrugated materials in order to reduce the impact of their products to the environment (see Hong et al. 2018) [8]. In Zhang et al. (2018) [9], they reported that some large food companies have adopted new technologies to reduce pollution. Using an environmentally extended micro-social accounting matrix (SAM) and a computable general equilibrium model (CGE), Meng, Siriwardana and McNeill (2013) [10] reported that a carbon tax of A $\$ 23$ per tonne of $\mathrm{CO}_{2}$ emissions (imposed on the Australian economy with exemption to agricultural, land transport and household sectors) cut emissions significantly but caused a mild economic contraction as measured by real gross domestic product (GDP) and real gross national product (GNP). Meng et al. [10] also found that when the revenue from carbon tax is fully and equally transferred to households, the effect of the compensation plan on $\mathrm{CO}_{2}$ emission was minimal. Effort to reduce carbon emission is widely observed in several industries including food and beverage, apparel, electronics and automobile industries. Wright, Hawkins, Orozco and Mabey (2018) [11] argued that shadow carbon pricing would encourage low carbon investment because it is used internally within financial appraisals to de-prioritize high emission projects and also because it did not incur actual costs unlike other carbon pricing policies like carbon taxes. They also argued that if shadow carbon pricing is set at the correct 
level, only projects compatible with low carbon emissions would be accepted and they suggested an adoption of a wider range of instruments since shadow carbon pricing cannot be used as an isolated tool for initiating a transformation. Further, Wright et al. (2018) [11] reported that the High-Level Commission on Carbon Prices (HLCCP, a World Bank initiative), carbon prices of $\$ 40-\$ 80$ per tonne of $\mathrm{CO}_{2}$ by 2020 and $\$ 50-\$ 100$ per tonne by 2030 would be required to keep global warming below $2^{\circ} \mathrm{C}$. In May 2017 PEMBINA Institute report, MacNab, Flanagan, Kniewasser and Hastings-Simon [12] reiterated the federal benchmark of the government of Canadian on carbon pollution and reported a guidance on treatment of the energy-intensive and trade-exposed industries (EITE) sectors and the protection of vulnerable Canadians. Niu, Chen and Zhang, 2017 [13] reported that Patagonia, an apparel company in the USA has made sustainable efforts to cut down the amount of carbon emission in its products. Ghosh and Shah, 2012 [14], posited that Adidas reduced the amount of hazardous material used in its manufacturing process and the amount of waste in its packaging. It is reported that from 2007 to 2015, Dell-EMC reduced its hazardous emission by an absolute $40 \%$ (see Ghosh and Shah, 2015) [15]. Kojima and Asakawa (2016) [16] discussed how carbon pricing could facilitate a low-carbon transition or a net zero carbon transition and they also reported that the expected benefits of carbon pricing that combines the introduction of carbon tax and reduction of other taxes, such as income taxes, is expected to achieve both environmental and socio-economic benefits.

Given that climate change is now widely viewed as a threat to the environment, economic growth and social welfare, and that the EU committed to reduce its emissions of $\mathrm{CO}_{2}$ by 25 percent in 2020 relative to 1990 levels, Rozenberg et al. suggested that the climate change externality could be managed through carbon certificates [17]. They argued that the cost of capital of low-carbon projects could be cheaper than the cost of capital of high-carbon projects if carbon certificates (instead of carbon tax) were created as part of a commercial bank's legal reserves and distributed to capital investment with low-carbon content. They further argued that the framework of carbon certificates is politically easier to implement than the more efficient carbon tax method. Brauneis, Mestel and Palan (2012) [1], using the Monte Carlo model, investigated the effect of different carbon price cap designs on an individual firm's choice of technology. Specifically they modeled the effect of a carbon price cap on the firm's choice (of energy) between a pulverized coal combustion plant, a combined cycle gas turbine plant, a hydropower plant, a solid biomass plant and an on-shore wind farm. They found that the level of the carbon price cap influenced the choice of technology and the timing of investments and that the adoption of a higher carbon price cap favored low technologies in general. Though there is anecdotal evidence that several manufacturers incur additional cost in an effort to reduce carbon emissions, Xiao et al. (2020) [18], investigated the optimal contract for sustainable supply chain participants by interactively analyzing the impact of re- 
tailers' fairness concern and manufacturers' overconfidence on carbon pricing, the cost of reducing carbon emission and the related profits to supply chain participants. Xiao et al. concluded that intensity in fairness concern decreased the effort to reduce carbon emissions and the profitability of the supply chain participants [18]. However, the simultaneous existence of fairness concern and manufacturers' overconfidence showed that the cost sharing contract generated higher profits for the retailer when the intensity in fairness concern is high. Panteghini and Scarpa (2003) [19] analyzed regulatory mechanism such as price caps or profit sharing and posited that regulatory risk may or may not affect investments decisions negatively. Hong, Wang and $\mathrm{Yu}$ (2018) [8], investigated the pricing of green products by taking into account consumer environmental awareness (CEA) and non-green product reference under three different scenarios; single-product-pricing, dual-product competition and asymmetric-information case and reported that the firm should adopt the distinguished pricing strategies in contrast to the asymmetric information. Zhang et al. (2018) [9] studied how the carbon cap and trade (CCT) mechanism affects competitive manufacturers' product design and pricing strategies using the Nash and Stackelberg game models respectively. They also discussed the impacts of the CCT-mechanism, consumer environmental awareness (CEA) and the sensitivity of switchovers toward price on the optimal carbon emission reduction rates, retail prices and manufacturers' profits. In its 2017 paper, the Union of Concerned Scientists [20] reported that California's Low Carbon Fuel Standard and Cap-and-Trade program played a major role in cutting global warming emissions from the state's transportation sector. Rafaty and Grubb (2018) [21] reported improvement in economic efficiency and environmental effectiveness of carbon pricing schemes by ensuring that the costs of $\mathrm{CO}_{2}$ emissions associated with production are fully passed through the value system. Further, Rafaty and Grubb (2018) [21] stated that a price on carbon consumption eliminated the risk of cross border carbon-leakage by incorporating extra-territorial emissions and treated producers on a level playing field regardless of their jurisdiction of origin. Mann (2009) [22] reported that both cap-and-trade system and carbon taxes are market mechanisms that reduce demand for carbon-intensive goods by increasing their costs.

Other research papers that analyzed the impact of regulatory mechanisms on capital investments include Niemann (2011) [2] research where he stated that a higher expected tax payment could delay capital investments. Niemann also found that pre-tax cash flows and tax payments are positively correlated; in other words, an increase in pre-tax cash flows will increase the amount of taxes to be paid by the investor. In addition, in market economies where tax uncertainty is low, an increase in tax uncertainty is likely to increase the rate and level of capital investment. However, Niemann argued that the effect of a higher after tax discount rate on the timing of capital investment is ambiguous. Schneider and Sureth (2010) [23] study on capital investments which examined managerial 
options to invest or divest showed that increasing the tax rate on cash flows could increase the investor's willingness to invest. Though Schneider and Sureth [23] results seem contrary to the effect of taxes on capital investments, it does imply that an investor may increase the rate of capital investment in order to absorb the increase in the tax rate.

This paper contributes to the existing literature because we analyze how the imposition of unexpected carbon tax could affect expected cash flows and simultaneously, how the anticipated technological changes could affect the decision of investors to invest in irreversible projects in a real options model. Though research studies on option pricing models in financial investments and natural resources abound, there is no research which analyzes the joint impact of uncertainties in technology and carbon tax on investment behavior and this paper makes that contribution. Theoretically, the real options model show that when returns are uncertain (that is, returns exhibit some random walk component) and costs are sunk and irreversible, that the required returns of investments are expected to be significantly higher than in standard expected net present value (E(NPV)) models (Dixit and Pindyck, 1994) [7]. Thus the real options model provides a reasonable explanation of the friction in investments decisions and uncertainties in regulation and technology.

Under the standard expected net present value approach, managers invest when the present value of the discounted incremental stream of free cash flows from the capital invest exceeds the investment's weighted average cost of capital. With the real options approach, investment decisions are contingent upon obtaining more information about potential changes in regulation, technology and capital markets and the effects of these factors on future cash flows before making the irreversible investment decision.

The literature on stochastic investing decisions began in the 1980s with papers such as Malliaris and Brock (1982) [24], Miller and Voltaire (1983) [25] and Brock and Rothschild (1984) [26]. These research studies developed models that showed how investment rules and asset values can be determined when the expected cash flows generated by the investment follows a geometric Brownian motion (GBM) process expressed as

$$
\frac{\mathrm{d} \pi}{\pi}=\alpha \mathrm{d} t+\sigma \mathrm{d} z
$$

where $\pi$ refers to after tax cash flows expected from a capital investment, $\alpha$ is the constant drift rate, $\sigma$ the constant variance, $\mathrm{dz}$ is the increment of a standard Wiener process, i.e., $\mathrm{d} z=\varepsilon_{t} \sqrt{t}$ and $\varepsilon_{t}$ is $N(0,1)$ and $E\left(\varepsilon_{t}, \varepsilon_{s}\right)=0$ for $t \neq s$.

The Black-Scholes (1973) [27] option pricing model is a classic example of a model based on a geometric Brownian motion. By definition, however, the GBM is restricted to only positive values. In real option theory, it is plausible that capital investments may yield both positive and negative incremental after tax cash flows. As a result of the restriction [2] suggested that the arithmetic Brownian 
motion should be the preferred approach used in modelling stochastic investment decisions. In general, cash flows are the difference between expected earnings and expected expenditures and both earnings and expenses can be modelled as separate geometric Brownian motions. However, the mathematical properties of the differences of the two separate GBMs are inconvenient. An alternate stochastic model is the Poisson or Jump processes characterized by infrequent discrete jumps rather than continuous time albeit with small variations. Because cash flows of large capital projects are affected by several random economic variables, variations of these economic variables cannot be modelled as "Jump" events. Therefore, a stochastic process with continuous variation is preferred to the Jump processes.

For ease of analysis, our model assumes that unanticipated changes in legislation on carbon tax may trigger changes in technology; howbeit, the speed at which a new technology would be adopted by an investor is beyond the scope of this paper. If the legislation on carbon tax is muted and stochastic cash flows follow GBM, the NPV rule and an analytical solution are feasible. The investment decision would be akin to a real option analysis similar to an American call option.

Microeconomic reasoning suggests that if the expected cash flow is high, other investors will enter the market putting downward pressure on expected cash flow and vice versa. Also, under the GBM process, if expected cash flow is zero, it will remain at zero against standard expectation. This characteristic of the GBM would affect the value of the option at lower levels of cash flows suggesting that the estimated value of the option may be inaccurate.

The rest of the paper is organized as follows. Section 2, discusses the economic theory of carbon tax including the social cost of carbon emissions followed by the structural model in Section 3 where we mathematically analyze the effect of carbon tax on expected cash flows and the resulting technological innovation and how both factors could impact the value of irreversible capital investments. In Section 4, we explain the geometric Brownian motion as a binomial process and in Section 5 we use the continuous time finite-horizon dynamic programming to analyze the effect of carbon tax on cash flows and the related technological changes in irreversible capital investments, concluding remarks in Section 6, references in Section 7 and appendix in Section 8.

Hypothesis: Would unexpected changes in regulation and technology negatively or positively impact the expected cash flow and value of irreversible capital investments?

\section{The Economic Theory of Carbon Tax}

Carbon tax is a tax levied on the carbon content of fuels. It is a form of carbon pricing. Many scientists have argued that the global warming effects of greenhouse gases (GHGs) released into the atmosphere are caused by the combustion of fossil fuels. These GHGs include pesticides, fertilizers, fuels and oils for trac- 
tors, equipment, trucking and shipping, electricity for lighting, cooling, heating, methane and nitrous oxide. Methane and nitrous oxide are respectively $21 \mathrm{x}$ and 310x more damaging as GHGs than $\mathrm{CO}_{2}$ (Griffith et al., 2008) [28]. A tax on these emissions can be levied by taxing the carbon content of fossil fuels at any point in the product cycle of the fuel.

While there is pressure on the government of the USA to curb the greed in Wall Street, banking, insurance and housing by enforcing the existing regulations, industrial agriculture which is one of the largest producers of methane and nitrous oxide, and arguably one of the most polluting industries remains unregulated for the last thirty years. The USA Environmental Protection Agency (EPA) estimated in 2007 that industrial agriculture was responsible for about $18 \%$ of the carbon footprint in the United States (Allen and Pantzalis, 1996) [29].

A carbon tax as a form of pollution tax is often grouped with two other economic policy instruments: tradable pollution permits or credits and subsidies. These three environmental economic policy instruments are governed on the principle of a command and control regulation. The difference is that classic command-penalty regulations stipulate, through performance and standards, what each polluter is expected to do in order to be in compliance with the regulation. The difference between a tax and a command and control regulation depends on whether the enacted legislation contains the word "tax".

A carbon tax is also a tax on a transaction, that is, a price paid for performing a specific transaction. It sets a price to be paid based on carbon dioxide emissions from a transaction. Arthur Pigou (1920) [30] most enduring contribution was The Economics of Welfare, in which he introduced the concept of externality and the idea that externality problems could be corrected by the imposition of a Pigovian tax (also spelled "Pigouvian tax"). In The Economics of Welfare (initially called Wealth and Welfare), Pigou developed Marshall's concept of externality, which is a cost imposed or benefit conferred on others that are not accounted for by the person who creates these costs or benefits. Pigou argued that negative externalities (costs imposed) should be offset by a tax, while positive externalities should be offset by a subsidy. In the early 1960s Pigou's analysis was criticized by Ronald Coase [31], who argued that taxes and subsidies are not necessary if the partners in the transaction can bargain over the transaction. The externality concept remains central to modern welfare economics and particularly to environmental economics. The Pigou Club, named in his honor, is an association of modern economists who support the idea of a carbon tax to address the problem of climate change. Thus, the economist Arthur Pigou proposed taxing the goods (i.e., hydrocarbon fuels) which are the source of carbon dioxide emissions so as to accurately reflect the cost of carbon dioxide in emissions to the society. A tax on a negative externality is called the Pigouvian tax and it should be equal to the marginal cost of the expected damage. The effect of carbon tax could significantly reduce the growth rate of capital investments. On the other hand, a carbon tax could accelerate the growth in technological inno- 
vation in non-combustible and renewable sources of energy such as wind, solar, ethanol and geothermal.

The social cost of carbon (SCC) is the marginal cost of emitting one extra tonne of carbon dioxide (equal to 1000 kilograms or 1 megagram of $\mathrm{CO}_{2}$ ) at any point in time. In order to estimate the SCC, the atmospheric residence time of carbon dioxide must be estimated together with an estimate of its impacts of climate change. The effect of an extra tonne of carbon dioxide in the atmosphere must then be converted to equivalent impacts when the tonne of carbon dioxide is emitted. In economics and finance, comparing impacts over time require a discount rate which determines the weightings on the impacts occurring at different times.

According to economic theory under perfect market conditions, carbon tax should be set equal to the SCC. Emission permits should also have a value equal to the SCC. However, markets are not perfect and estimates of SCC are highly uncertain with an average value of $\$ 43 / \mathrm{tC}$ (" $\mathrm{tC}$ " equals a tonne of carbon) and a standard deviation of $\$ 83 / \mathrm{tC}$ (see Yohe et al., 2007) [6]. The variability of estimates is attributed to the uncertainties in the science of climate change, different assumptions on the appropriate discount rate and the resulting different valuation of economic and non-economic impacts, the treatment of equity and how potential catastrophic impacts are estimated. Other estimates of SCC ranged less than $\$ 1 / \mathrm{tC}$ to over $\$ 1500 / \mathrm{tC}$. The true SCC is expected to increase over time at a rate of two percent to four percent per year (Yohe et al., 2007) [6].

It is also important to discuss the effect of carbon leakage; that is the effect that regulation of emissions in one country/sector has on the emissions in other countries/sectors that are not subject to the same regulation. Baker et al. (2007) [32] posited that leakage effects can be positive or negative. The leakage effect can be positive if it reduces the effectiveness of reducing overall emissions and negative if it increases the effectiveness of reducing overall emissions. A desirable negative leakage would occur due to a reduction in the demand for coal, oil and gas from the developed countries and the result would be a lowering of world prices of these hydrocarbon fuels. This will lead to developing countries being able to substitute oil for gas, or gas for coal (and vice versa) at reduced prices which effectively will reduce national emissions. However, if the transfer of less polluting technologies is delayed, this substitution effect will have no long term benefits.

Regulatory policies such as border tax adjustments, trade tariffs and trade bans have been suggested to address issues over competitive losses when one country imposes a carbon tax and the other country does not (see Gupta, S. et al. 2007) [33]. Border tax adjustments account for emissions attributed to imports from countries without a carbon price. The alternative involves trade bans and/or tariffs applied to non-carbon taxing countries. Gupta et al. (2007) [33] further argued that such approaches could be disadvantageous to a target country as a trade measure. To date, the World Trade Organization (WTO) case law 
has not provided specific rulings on climate-related taxes.

\section{Modeling the Option to Invest in Irreversible Investments}

The decision to invest now or postpone investing to a later period is modeled from the perspective of an environmentally-sensitive-investor. The investment time frame is restricted to one-period investment. The numerical method used could be extended to a sequential investment case; however the solution to a sequential investment problem will involve a two-dimensional degenerate parabolic partial differential inequality which is beyond the scope of this paper.

A capital investment is expected to generate incremental revenues as well as incur incremental (explicit and implicit) operating costs. The result is a forecast of after tax incremental cash flows from the capital investment. This paper analyzes the effect of regulatory uncertainty (such as the imposition of carbon tax on cash flows from an investment, as an additional tax) and a related change in technology on the decision to invest in an irreversible capital project. We begin by assuming that the after tax cash flows (before the additional tax on carbon is imposed) follow some known stochastic process expressed as:

$$
\frac{\mathrm{d} \pi}{\pi}=\alpha \mathrm{d} t+\sigma \mathrm{d} z
$$

where $\pi$ refers to incremental after tax cash flows expected from a capital investment (before carbon tax), $\alpha$ is the constant drift rate, $\sigma$ the constant variance, $\mathrm{d} z$ is the increment of a standard one dimensional stochastic Wiener process, also called a Brownian motion, i.e., $\mathrm{d} z=\varepsilon_{t} \sqrt{t}$ and $\varepsilon_{t}$ is $N(0,1)$ and $E\left(\varepsilon_{t}, \varepsilon_{s}\right)=0$ for $t \neq s$.

An irreversible investment means that the investment cannot be abandoned during its economic life ending at time $T ; T$ may be finite or infinite. We assume that the capital investment does not include any additional flexibility or externality, so the only benefit is the expected net cash flow from the capital investment. We also assume that the after-tax cash flows, $\pi_{t}$, and carbon tax are stochastic. This special case is frequently used in the literature because it permits an analytical solution.

We adapt the dynamic programming model to determine the optimal timing of the investment that would maximize the investment's cash flows and the value of the irreversible capital investment again assuming that an additional tax could be imposed (on the after tax cash flow of the investment) as a result of the carbon content of the investment and the potential exits that there will be new technology adapted to minimize the carbon content of the irreversible capital investment.

A celebrated application of Richard Bellman's dynamic programming equation of 1940 can be found in Robert C. Merton's seminal 1973 [34] article on the inter-temporal capital asset pricing model. Dynamic programming method was originally developed and used by Richard Bellman in the 1940s to derive the optimum solution of time-varying investments. Since then, dynamic programing 
has been used to derive solutions to problems exhibiting properties of overlapping sub-problems. Therefore, it is a convenient method used for solving complex problems because dynamic programming breaks down the problem into simpler sub-problems. Another method used in analyzing time-varying investments is the "greedy" algorithm which picks the best possible solution "at any possible branches in the road". Though the greedy algorithm may provide a faster solution to a time varying investment, it does not guarantee the optimal solution.

Because economic applications of dynamic programming usually result in a Bellman equation which is a differential equation, economists refer to dynamic programming as a "recursive method" used in solving a wide range of problems in economics and finance including business valuation, asset pricing, principal-agent problems, monetary and fiscal policy, labor economics, public finance and capital budgeting.

To formalize our dynamic programming model, we assume that the after tax cash flow at time $t$ be $\pi_{t}$; so the initial after tax cash flow at time, 0 , is $\pi_{0}$. We assume that the after tax cash flow will change from $\pi_{0}$ to a new state $\Delta \pi, t$ when a new action, e.g., carbon tax, $\tau$ is imposed. We also assume that the response to the imposition of carbon tax could be the adoption of a new technology, $K(t)$ designed to minimize the impact of carbon tax, and at the terminal condition, $K(t)+\Delta t=0$. We also refer to $\delta$ as the instantaneous and unobservable discount rate which could complicate the analytical solution. In The Stern Review on the Economics of Climate Change, Weitzman (2007) [35] reported that though the Stern Review called for "immediate decisive action to stabilize greenhouse gases because the benefits of strong early action on climate change outweighs the costs" by adopting a very low discount rate for investments on climate change and secondly that it might be important to avoid large uncertainties that are difficult to quantify, Weitzman argued "that spending money to slow global warming should perhaps not be conceptualized primarily as being about consumption smoothing as much as being about how much insurance to buy to offset the small change of a ruinous catastrophe that is difficult to compensate by ordinary savings" [35].

The Bellman equation is given as follows (see Merton, 1973 [34]):

$$
V\left(\pi_{t}, t\right)=\max \left\{\pi_{t}-\tau, K(t) \Delta t+(1+\delta \Delta t)^{-1} E\left[V\left(\pi_{t}+\Delta \pi, t+\Delta t\right)\right]\right\}
$$

Following Dixit and Pindyck (1994) [7] for each time period $t$, a critical value of $\pi_{t}^{*}$ exists such that investing is optimal when $\pi_{t}>\pi_{t}^{*}$ and vice versa. Thus the solution to the investment problem involves finding the free boundary when, $\pi_{t}=\pi_{t}^{*}$.

Equation (1) is a differential equation and is a time-dependent function of a stochastic process. Applying Ito's Lemma and assuming in the limit that, $\Delta t \rightarrow 0$, we derive a partial differential equation which satisfies the value function, $\delta V\left(\pi_{t}, t\right)$ in the continuation region: 


$$
\delta V(\pi, t)=K(t)+V_{t}+\alpha V_{\pi}+\frac{1}{2} \sigma^{2} V_{\pi \pi}
$$

Similar to Insley (2002) [36], our optimal investment problem can now be formulated as a linear complementarity problem, denoting the time remaining (i.e., the continuation region which keeps the option alive) as $s=T-t$ as:

$$
R V \equiv \delta V(\pi, s)+V_{s}-\alpha V_{\pi}-\frac{1}{2} \sigma^{2} V_{\pi \pi}-K(T-s)
$$

The linear complementarity problem can be specified as:

(i) $R V \geq 0$

(ii) $V(\pi, s)-(\pi-\tau) \geq 0$

(iii) $R V[V(\pi, s)-(\pi-\tau)]=0$

Part (i) of the linear complementarity problem specifies that the expected value of the investment, $\delta \mathrm{V}$ must exceed its current value in order to exercise the option to justify delaying the investment pending carbon tax or no carbon tax. In other words, the holding value, $R V$ must be greater or equal to zero. When $R V=0$, the option to invest is "at-the-money" and investor is better-off holding unto the option. When $R V>0$, the option to invest is "in-the-money" and investor is better-off exercising the option; and when $R V<0$, the option to invest is "out-of-the-money" and this outcome is not expected to persist in a competitive market environment in the long term.

Part (ii) of the linear complementarity problem states that the value of the option to delay investing while in the continuation region, $V(\pi, s)$, should always exceed the value of the payout in the event of a carbon $\operatorname{tax}, V(\pi-\tau)$. This finding is consistent with the behavior of a rational investor holding an American-type call option. The option can be exercised at any time in the continuation region, $s$, if the value of the option post carbon tax is greater than zero; and the option would be exercised immediately if the value of option decreases to the level of the payout.

Part (iii) of the linear complementarity problem states that part (i) or (ii) or both could hold as a strict equality. If $R V=0$ and $V(\pi, s)-(\pi-\tau)=0$, then the value of investing now is equal to the value of waiting; therefore the investor will be indifferent.

To obtain a numerical solution of Equation (4), we need to specify the following boundary conditions.

\section{Boundary Condition I.}

We assume that carbon tax rate may negatively affect expected cash flows and as a result, the value of the investment will be negatively impacted such that, $\lim _{\pi \rightarrow 0} V(\pi, s)=-\tau$.

Thus, Equation (3) can be rewritten as:

$$
R V \equiv \delta V(\pi, s)+V_{s}-\alpha V_{\pi}-K(T-s), \pi \rightarrow 0
$$

Noting that part (iii) of Equation (4) suggests that both $R V=0$ and $V(\pi, s)-(\pi-\tau)=0$, by substitution Equation (5) above becomes 


$$
R V=\alpha V_{\pi}-\delta V(\pi, s)+K(T-s), \pi \rightarrow 0
$$

Equation (6) states that the value of the investment could depend on the adoption of a new technology as a response to the imposition of carbon tax. Again, the path and timing of such technological adoption are beyond the scope of this paper.

At the optimal investment stage, part (ii) of Equation (4) becomes an equality. At that stage, the value of the option will be equal to the payout. This result again supports the argument that carbon tax has negative effect on capital investments.

\section{Boundary Condition II.}

When the after-tax cash flow gets larger, $\lim _{\pi \rightarrow \infty} V(\pi, s)=\tau$, the value of the option to invest becomes a function of timing and flexibility of the investment's landscape.

Thus $V(\pi, s)=\gamma(s) \pi$ and $V_{\pi}=\gamma(s)$ represents timing and flexibility. As $\pi \rightarrow \infty$ the upside potential for the option is limited and compressed. The value of option at this stage is proportional to the investment's cash flows, $\pi$ implying that the value of the investment is a function of timing and the decision of the investor; thus $V_{\pi}=\gamma(s)$ and $V_{\pi \pi}=0$. Substituting this result into Equation (3), we obtain

$$
R V \equiv \delta V(\pi, s)+V_{s}-\alpha V(\pi, s)-K(T-s), \pi \rightarrow \infty
$$

If the option to invest stays in the continuation region, then $R V=0$ and Equation (7) can now be expressed as

$$
\begin{gathered}
V_{s}=\alpha V(\pi, s)-\delta V(\pi, s)+K(T-s), \quad \pi \rightarrow \infty \\
V_{s}=V(\pi, s)[\alpha-\delta]+K(T-s)
\end{gathered}
$$

However, if $R V>0$ indicating that investing is optimal, then part (ii) of the linear complementarity formulation is confirmed. Ignoring any further technological improvements given that after-tax cash flows are sufficiently large, we obtain

$$
\begin{gathered}
V(\pi, s)-\pi=0 \\
(\gamma(s)-1) \pi=0, \quad \gamma(s) \rightarrow 1
\end{gathered}
$$

And, as the investment cash flow increases, $\gamma=1.0$

In the numerical solution section of this paper, that is Section 5 , we choose an arbitrarily value for cash flow and the result shows that increasing the size of the cash flow does not change the results significantly and the effect of carbon tax is ambiguous, that is, when the after-tax cash flow increases, the value of the investment does not change significantly even after the imposition of carbon tax; secondly, the effect of any technological change is mute (see Table 1 and Figure 1 in the Appendix).

\section{Boundary Condition III the terminal boundary.}

As $T \rightarrow 0, \lim _{s \rightarrow 0} V(\pi, s)=\max [\pi-\tau, 0]$ the value of the investment is expected to depend on the investment's after tax cash flows following the adoption 
of a new technological.

As control, we show that the value of the investment will depend on the investment's after-tax cash flows with no carbon tax imposed and no technological improvement whichever is larger. Thus,

$$
V(\pi, s=0)=\max [\pi-\tau, 0]
$$

The numerical approach used to determine the value of the option is a finite difference method which involves the reduction of a continuous partial differential equation into a discrete set of finite difference equations. The choice of a discretization approach should recognize the properties of stability and convergence; stability to minimize small errors arising from finite computer arithmetic and convergence as the solutions to the results do not change significantly if the after tax cash flows get larger. The linear complementarity formulation of the analysis makes it feasible for us to analyze the investment decision at each time (i.e., node) using the penalty method (Zvan, R., Forsyth, P.A., and K.R. Vetzal, 1998) [37]. The Zvan et al. [37] approach is an improvement over the traditional Crank-Nicholson method of successive over relaxation (SOR) approach discussed in Paul Wilmott (1998) [38], "Derivatives: The theory and practice of financial engineering". The penalty method is an efficient means of imposing the condition that the value of the option to wait cannot be less than the payout, that is $V(\pi, s)-\left(\pi_{t}-\tau\right) \geq 0$.

\section{The Investment Decision under Gbm}

In this section we show that the timing of an irreversible capital investment is independent of the investment's expected after-tax cash flows especially when carbon taxes and the adoption of new technological are ignored. This finding is analogous with the findings of Reed and Clarke, 1990 [39]; Insley 2002 [36]. The parameters of the generalized stochastic process under GBM are specified as:

$\frac{\mathrm{d} \pi}{\pi}=\alpha \mathrm{d} t+\sigma \mathrm{d} z_{\pi} ; \alpha$ and $\sigma$ represent the drift rate and variance respectively.

Equation (3) can be restated as:

$$
R V \equiv \delta V(\pi, s)+V_{s}-\alpha V_{\pi}-\frac{1}{2} \sigma^{2} \pi^{2} V_{\pi \pi}-\alpha \pi V_{\pi}-K(T-s)
$$

To determine the numerical solution we specify the value of the option when the time remaining in the life of the option, $s$, equals zero. Working backward from that point, the value of the option is determined at each node back to the present period.

When $s=0$, the terminal condition states that the value of the option is just the maximum of the payoff $\left[\pi_{t}-\tau\right]$ or 0 .

$$
V(\pi, s=0)=\max [\pi-\tau, 0]
$$

In other words, the value of option in the terminal period is equal to the in- 
vestment's cash flow less carbon tax. At this stage, part (ii) of the linear complementarity problem holds as a strict equality and $R V \geq 0$. With $V_{\pi}=1$ and $V_{\pi \pi}=0$ substituted into Equation (4) and Equation (11), $V_{s}$ at $s=0$ becomes:

$$
V_{s} \geq \max [0, \pi(\alpha-\delta)+\delta \tau+K]
$$

By inference $V_{s}$ cannot be negative at the terminal period because value is at its minimum pending if carbon tax will be imposed, i.e., $V(\pi, s=0)=\max [\pi-\tau]$. However, $V_{s}$ will be greater than zero if the second term, $\pi_{t}(\alpha-\delta)$ is positive. In addition, if the tax rate, $\tau / \pi$ is zero, then we need only to be concerned with the sign of the second expression because there will be no justification for the adoption of a new technology and $K=0$.

In practice, investors prefer the rate of increase in $\pi_{s}$ to be larger at the early stages and monotonically decline over time as $s=0$. As $s$ increases (moving backward in time) both the drift rate and after-tax cash flows will also increase. The optimal investment time is therefore at the point where $V_{s}$ becomes positive, moving backward in time.

Special case 1: when $\tau$ is zero.

The optimal investing time depends on the drift rate and is independent of the level of the after tax cash flows, $\pi_{s}$. Based on these findings, the cost of delaying the investment is equivalent to the delay in generating $\pi_{s}$, measured by $\delta$ the instantaneous discount rate; while the benefits of delaying investing include the increase in $\pi_{s}$ due to the expected increase in the drift rate.

Special case 2: when $\tau$ is not zero.

If the tax rate, $\tau / \pi$ is not zero, then the sign for $V_{s}$ cannot be determined in advance and the timing of investment will depend on the stochastic variable $\pi_{s}$. However, if carbon tax, $\tau$ is small, then ignoring both $\tau / \pi$ and $\pi$ would not significantly impact the timing of the optimal investment decision.

Re-stating our model, we make the following assumptions that regulatory uncertainty means carbon tax levied on capital investments and such taxes will impact expected cash flows from the project. The response or reaction by investors could be either change and adopt a new technology or do nothing and stay the course (see Table 2, Figure 2, and Table 3, Figure 3).

By notation, $\pi_{t}$ refers to after tax cash flow and follows GBM, $\frac{\mathrm{d} \pi}{\pi}=\alpha \mathrm{d} t+\sigma \mathrm{d} z ; \quad K_{t}$ represents new technology (to minimize the impact of Carbon tax). The Bellman equation is given as follows.

$$
V\left(\pi_{t}, t\right)=\max \left\{\pi_{t}-\tau, K(t) \Delta t+(1+\delta \Delta t)^{-1} E\left[V\left(\pi_{t}+\Delta \pi, t+\Delta t\right)\right]\right\}
$$

where $\delta$ is the instantaneous discount factor.

Thus, we re-affirm Dixit and Pindyck (1994) [7] by stating

Lemma 1: For every $t$, there exists a threshold $\pi_{t}^{*}$ such that 


$$
\begin{gathered}
V(\pi, t)=K(t) \Delta t+(1+\delta \Delta t)^{-1} E\left[V\left(\pi_{t}+\Delta \pi, t+\Delta t\right)\right] \text { for every } \pi \leq \pi_{t}^{*} \\
V(\pi, t)=\pi-\tau \text { for every } \pi \geq \pi_{t}^{*}
\end{gathered}
$$

And the boundary conditions are:

(i) $V(\pi, t)=\pi-\tau$ for all $\pi \geq \pi_{t}^{*}$

(ii) $V(\pi, s)-\pi=0$

(iii) $V(\pi, \tau=0)=\max [\pi-\tau, 0]$

Next, we illustrate how the adoption of a new technology over time could impact the value of an irreversible capital investment, first by assuming that change in technology follows a path whereby $K(t) \equiv K$. As such, we propose Lemma 2:

Proposition I of Lemma 2: $V(\pi, t)$ is decreasing in time, $t$.

Proof:

We set the boundary condition $V(\pi, T)=\max [\pi-\tau, 0]$ for all $\pi$

$$
\begin{gathered}
V(\pi, T-\Delta t)=\max \left\{\pi-\tau, K \Delta t+(1+\delta \Delta t)^{-1} E[V(\pi+\Delta \pi, 0)]\right\} \\
V(\pi, T-\Delta t) \geq \max [\pi-\tau, 0]=V(\pi, T)
\end{gathered}
$$

By inference, we show that the value of an investment is decreasing in time. Further we assume for all $t \geq t^{\prime}$ and $\pi$ there exists $V(\pi, t) \geq V(\pi, t+\Delta t)$.

Next, we show that for $t=t^{\prime}-\Delta t$, it is true that $V\left(\pi, t^{\prime}-\Delta t\right) \geq V\left(\pi, t^{\prime}\right)$. Based on these two functions;

$$
\begin{aligned}
& V\left(\pi, t^{\prime}\right)=\max \left\{\pi-\tau, K \Delta t+(1+\delta \Delta t)^{-1} E\left[V\left(\pi+\Delta \pi, t^{\prime}+\Delta t\right)\right]\right\} \\
& V\left(\pi, t^{\prime}-\Delta t\right)=\max \left\{\pi-\tau, K \Delta t+(1+\delta \Delta t)^{-1} E\left[V\left(\pi+\Delta \pi, t^{\prime}\right)\right]\right\}
\end{aligned}
$$

Combining the 2 functions above with the assumption that

$V\left(\pi+\Delta \pi, t^{\prime}\right) \leq V\left(\pi+\Delta \pi, t^{\prime}+\Delta t\right)$ we obtain

$$
V\left(\pi, t^{\prime}-\Delta t\right) \geq V\left(\pi, t^{\prime}\right)
$$

The results show that $V(\pi, t)$ is decreasing in $t$. This finding further confirms that if $K(t) \equiv K$, investors would prefer a higher rate of increase in cash flows at the early stages of an investment economic lifecycle. Proposition I of Lemma 2 can be extended to the case that $K(t)$ is decreasing over time, $t$.

Proposition II of Lemma 2: $V(\pi, t)$ is increasing in $\pi$.

Proof: We know from the boundary condition that $V(\pi, T)=\max [\pi-\tau, 0]$. Now we assume for all $t \geq t^{\prime}$, we show that $V(\pi, t)$ increases in $\pi$. When $t=t^{\prime}-\Delta t$, we obtain

$$
V\left(\pi, t^{\prime}-\Delta t\right)=\max \left\{\pi-\tau, K \Delta t+(1+\delta \Delta t)^{-1} E\left[V\left(\pi+\Delta \pi, t^{\prime}\right)\right]\right\}
$$

Noting that both terms of the right side are increasing in $\pi, V(\pi, t)$ is increasing in $\pi$ as the adoption of a new technology could mitigate the negative effects of carbon tax. Proposition II of Lemma 2 can be extended to the case with any function $K(t)$ (see Table 4, Figure 4). 
Proposition III of Lemma 2: $\pi_{t}^{*}$ is increasing in $t$.

Proof: From Lemma 1, the solution for $\pi_{t}^{*}$ is:

$$
\pi-\tau=K \Delta t+(1+\delta \Delta t)^{-1} E[V(\pi+\Delta \pi, t+\Delta t)]
$$

Note that the right side of the above equation is decreasing in $t$ but increasing in $\pi$. Therefore, the solution of $\pi_{t}^{*}$ is increasing in $t$ which suggests that with the adoption of a new technology (as a mitigating factor for carbon tax), $\pi_{t}{ }^{*}$ will increase in $t$. Proposition III of Lemma 2 can be extended to the case that $K(t)$ is increasing over time, $t$ (see Table 5, Figure 5).

\section{The GBM: As a Binomial Process}

Following Black and Scholes (1973) [27] and Insley (2002) [36] we assume that cash flows $\pi_{t}$, follow a GBM process which is a consistent assumption in financial economics. So, in this paper we assume that cash flows follow a lognormal diffusion process and the model underlying the process is

$$
\frac{\mathrm{d} \pi}{\pi}=\alpha \mathrm{d} t+\sigma \mathrm{d} z_{\pi}
$$

The maximum likelihood estimates of the drift $\alpha$, and the variance, $\sigma$ for cash flows can be stated as $\alpha=m+0.5 \sigma^{2}$ where $m$ is the mean of the series $\pi_{t}-\pi_{t-1}$. When we adopt Insley's estimates for $\alpha=0.01$ and $\sigma=0.13$, the validity of our results and conclusion did not change (also, see Table 5, Figure 5). Further, a base discount of $5 \%$ is also used.

The value of option to invest is derived explicitly by solving the underlying partial differential equation involving the binomial option pricing model developed independently by Cox, Ross and Rubinstein (1979) [40]. In a two-state option pricing model, the stochastic process described above is replaced with a discrete state assuming an increase (up) or decrease (down) movement in cash flows. Based on that assumption, we describe the binomial option pricing model as follows.

The initial cash flows are $\pi$. In the next period, $\pi$ will either increase to $u * \pi$ (upstate) or decrease to $d * \pi$ (down state). The probability of an upstate is $p$ and the probability of downstate is $1-p$.

The inference is that $u>1.0 ; d<1.0$. In other words, the proportional increase in the cash flow when there is an up movement is $u-1.0$; and the proportional decrease in the cash flow when there is down movement is $1.0-d$.

The probability of reaching the next period therefore is 1.0 because at that stage the investment could be implemented or delayed.

The expected value of the investment is a function of the expected cash flow, the effect of carbon tax on the expected cash flows and the impact of adopting a new technology that would mitigate the effect of carbon tax on the expected cash flows, all discounted at the appropriate discount rate. However, the uncertainty in the cash flow could be exacerbated by the imposition of carbon tax and the associated technological change. Therefore at any point in time $t$, the stochastic 
process could be described by two states: the first state being the expected cash flow from the investment and the second state is the expected cash flow given the imposition of carbon tax and the adjoining technological change designed to mitigate the effect of carbon tax on the cash flows. The binomial option pricing model specifies the cash flow process and the expected values of the investment can be explicitly determined at discrete nodes as long as the discount rate is known.

Using the dynamic programming formulation, the values of an investment can be evaluated at each stage. At each stage the decision maker must evaluate whether the investment is financially valuable or not. If the discounted value of investing today $(t)$ exceeds the discounted value of waiting, the managerial decision will be to invest today. For risk neutral valuation, the following equation states the appropriate recursive condition at any cash flow in the binomial tree as:

$$
\begin{gathered}
V(\pi, \tau)=\operatorname{Max}\left\{\pi_{t}-(1-\tau), K_{t} \Delta t+(1+\delta \Delta t)^{-1} p E\left[u, V\left(\pi_{t}, \Delta \pi_{t} t\right) \Delta \tau\right]\right. \\
+(1-p) E[d, V(\bullet)+\Delta \tau]\}
\end{gathered}
$$

where $E[u, V(\bullet)+\Delta \tau]$ is the expected value of the investment one year from now given that an upstate has occurred and vice versa. This valuation can then be expressed as Max $\left[\right.$ Invest $_{u}$, Wait $\left._{u}\right]$.

[ Invest $\left._{u}\right]=u * \pi_{t}(1-\tau), K_{t} \Delta t$ suggests that cash flow is expected to increase in the next period given the change in technology and [ Wait $\left._{u}\right]$ is the present value of the investment in $t=2$ period if the upstate occurred and the investment decision is to delay or postpone the investment. Conversely, $E[d, V(\bullet)+\Delta \tau]$ is the value of the investment one year from now given that the down-state occurred. Other variables are as stated earlier.

If at any node the investment value exceeds the value of delaying the implementation of the investment, the investment will be implemented. On the hand, if the value of delaying the investment is less than its current value, the investment will be abandoned at this time. Also, if the cost of the technology is greater than the value of investment, the investment will be abandoned as well. The estimated results therefore include the option of abandoning the investment if the value of the investment is too low to justify the cost of the technology plus the effect of the carbon tax. Formally, the value of the investment is computed as:

$$
\begin{gathered}
V(\pi, \tau)=\operatorname{Max}\left\{K_{t} \Delta t+(1+\delta \Delta t)^{-1} p E\left[u, V\left(\pi_{t}, \Delta \pi_{t} t\right) \Delta \tau\right]\right. \\
+(1-p) E[d, V(\bullet)+\Delta \tau]\}
\end{gathered}
$$

The equation above shows that the value of the investment depends on the expected values in future periods. Therefore, the future periods must be evaluated in order to determine whether it is optimal to invest now or delay investing to a later period. The dynamic analysis could be solved by backward induction to determine if the current value of the investment exceeds the discounted 
expected value of the next period best outcome. The boundary condition is the value of the investment in the final period.

\section{The Example}

A C++ program was written to solve the continuous time finite-horizon dynamic programming model requiring the following parameters; an initial cash flow estimate, the percent of carbon tax, the discount rate, the drift, the volatility, the terminal period and a function for new technology adopted by the investor as an attempt to mitigate the effect of carbon tax on the value of the investment. All values are nominal.

With an initial cash flow of $\$ 10,000$ and carbon tax rate at $20 \%$, drift at 0.01 , volatility equals 0.13 , the discount rate at $5 \%$, terminal period 25 years and the function for technology is $K(t)=50 \mathrm{e}^{-b t}$ where $b t$ measures the effect of technology over time, our base model is illustrated model and depicted in Table 6, Figure 6 and Table 7, Figure 7.

$$
\pi=\$ 10000: \frac{\tau}{\pi}=20 \% ; \mathrm{d} \pi=0.01 \mathrm{~d} t+0.13 \mathrm{~d} z ; K(t)=50 \mathrm{e}^{-b t} ; \delta=5 \% ; T=25
$$

\section{Conclusions}

In this paper, we analyze the effect of uncertainties in regulation and technology on the value of irreversible capital investments using the geometric Brownian motion. Regulatory uncertainty is attributed to a carbon tax levied on the carbon present in every hydrocarbon fuel. These hydrocarbon fuels when burnt, release atmospheric carbon dioxide $\left(\mathrm{CO}_{2}\right)$ unlike non-combustion energy sources: wind, sunlight, hydropower and nuclear. While a carbon tax on hydrocarbon fuels used as a source of energy would be the theoretically ideal regulatory instrument for the abatement of carbon dioxide emissions, substitution effects between different sources of energy could be realized through innovation in technology.

Our optimal investment problem is formulated as a linear complementarily problem based on the differential of the Bellman equation, a time-dependent stochastic process. Three analytical solutions were derived from the linear complementarily problem; the first analytical solution states that the expected value of an irreversible investment must exceed its current value in order to exercise the option to delay the timing of the investment. In other words, the value of an irreversible investment must be greater or equal to zero. When value is equal to zero, the option to invest is "at-the-money" and investor is better-off holding unto the option; when value is greater than zero, the option to invest is "in-the-money" and investor is better-off exercising the option; and when value is less than zero, the option to invest is "out-of-the-money"; though, this outcome is not expected to persist in a competitive market environment. Secondly, the linear complementarily problem also states that the value of the option to delay investing while in the continuation region, should always exceed the value of the payout given carbon tax. This finding is consistent with the behavior of a 
rational investor holding an American-type call option. The option can be exercised at any time in the continuation region if the value of the option of post carbon tax is greater than zero. However, the option would be exercised immediately if the value of option decreases to the level of the payout. Thirdly, the linear complementarily problem finally posits that if the first and second linear complementarily solutions hold as a strict equality, then the value of investing now is equal to the value of waiting and the investor will be indifferent.

We also extend the results of Dixit and Pindyck (1994) [7] showing that the imposition of carbon tax will impact the decision to delay or postpone the implementation of an investment even when cash flows $\pi$ are greater than its critical value, $\pi^{*}$. However, the adoption of a new technology could mitigate the negative effects of carbon tax on the value of irreversible investments. In addition, we show that, assuming the threshold in technology is $K(t) \equiv K$, the value of an investment could decrease in time regardless of the technological change because investors typically would prefer a higher rate of increase in cash flows at the early stages of the economic lifecycle of an investment. Conversely, this paper also shows that though the adoption of a new technology could mitigate the negative effects of carbon tax on investment cash flows, the increase in cash flows would increase the likelihood of the increase in the value of an irreversible investment. The result is that value of an irreversible investment is expected to increase as cash flow increases. Further, an increase in cash flow as a result of a change in technology will increase the minimum required critical value for cash flow, $\pi^{*}$ in time for irreversible capital investments, therefore $\pi^{*}$ is increasing in time.

\section{Acknowledgements}

We are very grateful to James Ming Chen, the Justin Smith Morrill Chair in Law at Michigan State University, East Lansing, MI 48824 for his very helpful comments and contributions to this paper.

\section{Conflicts of Interest}

The authors declare no conflicts of interest regarding the publication of this paper.

\section{References}

[1] Brauneis, A., Mestel, R. and Palan, S. (2012) Does a Cap on the Carbon Price Have to Be a Cap on Green Investments? Empirica, 39, 217-231. https://doi.org/10.1007/s10663-012-9188-5

[2] Niemann, R. (2011) The Impact of Tax Uncertainty on Irreversible Investment. Review of Management Science, 5, 1-17. https://doi.org/10.1007/s11846-010-0042-5

[3] Niemann, R. and Sureth, C. (2005) Capital Budgeting with Taxes under Uncertainty and Irreversibility. Jhrbücher f. Nationalökonomie u. Statistik, 225, 77-95. https://doi.org/10.1515/jbnst-2005-0106

[4] Lee, S.-H. and Makhija, M. (2009) The Effect of Domestic Uncertainty on the Real 
Options Value of International Investments. Journal of International Business Studies, 40, 405-420. https://doi.org/10.1057/jibs.2008.79

[5] Alm, J. (1988) Uncertain Tax Policy. Individual Behavior and Welfare. AER, 78, 237-245.

[6] Yohe et al (2007) 20.6 Global and Aggregate Changes. In: Parry, M.L., et al., Eds., Perspectives on Climate Change and Sustainability, Climate Change 2007: Impacts, Adaptation and Vulnerability. Contribution of Working Group II to the Fourth Assessment Report of the Intergovernmental Panel on Climate Change. Cambridge University Press, Cambridge.

[7] Dixit, A.K. and Pindyck, R.S. (1994) Investment under Uncertainty. Princeton University Press, Princeton. https://doi.org/10.1515/9781400830176

[8] Hong, Z., Wang, H. and Yu, Y. (2018) Green Product Pricing with Non-Green Product Reference. Transportation Research Part E: Logistics and Transportation Review, 115, 1-15. https://doi.org/10.1016/j.tre.2018.03.013

[9] Zhang, L., Zhou, H., Liu, Y. and Lu, R. (2018) The Optimal Carbon Emission Reduction and Prices with Cap and Trade mechanism and Competition. International Journal of Environmental Research and Public Health, 15, 2570. https://doi.org/10.3390/ijerph15112570

[10] Meng, S., Siriwardana, M. and McNeill, J. (2013) The Environmental and Economic Impact of the Carbon Tax in Australia. Environmental Resource Economics, 54, 313-332. https://doi.org/10.1007/s10640-012-9600-4

[11] Wright, H., Hawkins, J., Orozco, D. and Mabey, N. (2018) Banking on Reform. Aligning Development Banks with the Paris Climate Agreement.

http://www.jstor.com/stable/resrep17705.17

[12] MacNab, J., Flanagan, E., Kniewasser, M. and Hastings-Simon, S. (2017) Putting a Price on Carbon Pollution across Canada: Taking Stock of Progress, Challenges, and Opportunities as Canada Prepares Its National Carbon Pricing Benchmark. Pembina Institute, Calgary. http://jstor.com/stable/resrep02881

[13] Niu, B., Chen, L. and Zhang, J. (2017) Sustainable Analysis of Supply Chains with Fashion Products under Alternative Power Structures and Loss-Averse Supplier. Sustainability, 9, 995. https://doi.org/10.3390/su9060995

[14] Ghosh, D. and Shah, J. (2012) A Comparative Analysis of Greening Policies across Supply Chain Structures. International Journal of Production Economics, 135, 568-583. https://doi.org/10.1016/j.ijpe.2011.05.027

[15] Ghosh, D. and Shah, J. (2015) Supply Chain Analysis under Green Sensitive Consumer Demand and Cost Sharing Contract. International Journal of Production Economics, 164, 319-329. https://doi.org/10.1016/j.ijpe.2014.11.005

[16] Kojima S. and Asakawa, K. (2016) Carbon Pricing: A Key Instrument to Facilitate Low Carbon Transition. Institute for Global Environmental Strategies. http://www.jstor.com/stable/resrep02915

[17] Rozenberg, J., Hallegate, S., Perrissin-Fabert, B. and Hourcade, J.-C. (2013) Funding Low-Carbon Investments in the Absence of a Carbon Tax. Climate Policy, 13, 134-141. https://doi.org/10.1080/14693062.2012.691222

[18] Xiao, Q., Chen L., Xie, M. and Wang, C. (2020) Optimal Contract Design in Sustainable Supply Chain: Interative Impacts of Fairness Concern and Overconfidence. Journal of the Operational Research Society. https://doi.org/10.1080/01605682.2020.1727784

[19] Panteghini, P. and Scarpa, C. (2003) Irreversible Investments and Regulatory Risk. 
CESifo Working Paper No. 934.

[20] Union of Concerned Scientists (2017) Carbon Pricing and Low-Carbon Fuel Programs: Two California Policies Critical to Reducing Emissions from Cars and Trucks. http://www.jstor.com/stable/resrep17283

[21] Rafaty, R. and Grubb, M. (2018) How Can Consumption-Based Carbon Pricing Address Carbon Leakage and Competitiveness Concerns? Climate Strategies.

[22] Mann, R. (2009) To Tax or Not to Tax Carbon-Is That the Question? Natural Resources and Environment, 24, 44-46.

[23] Schneider, G.T. and Sureth-Sloane, C. (2010) The Impact of profit Taxation on Capitalized Investment with Options to Delay and Divest. Arqus Quantitative Tax Research Discussion Paper No. 97. https://doi.org/10.2139/ssrn.2128272

[24] Malliaris, A.G. and Brock, W.A. (1982) Stochastic Methods in Economics and Finance. North-Holland, Amsterdam.

[25] Miller, R.A. and Voltaire, K. (1983) A Stochastic Analysis of the Tree Paradigm. Journal of Economic Dynamic Control, 6, 371-386. https://doi.org/10.1016/0165-1889(83)90060-X

[26] Brock, W.A. and Rothschild, M. (1984) Comparative Statics for Multinational Optimal Stopping Problems. In: Sonnenschein, H., Ed., Models of Economic Dynamics, Springer-Verlag Lecture Notes in Economics and Mathematical Systems, No. 264, Springer-Verlag, New York.

[27] Black, F. and Scholes, M. (1973) The Pricing of Options and Corporate Liabilities. Journal of Political Economy, 81, 637-654. https://doi.org/10.1086/260062

[28] Griffith, D.W., Bryant, G.R., Hsu, D. and Reisinger, A.R. (2008) Methane Emissions from Free-Ranging Cattle: Comparison of Tracer and Integrated Horizontal Flux Techniques. Journal of Environmental Quality, 37, 582-591. https://doi.org/10.2134/jeq2006.0426

[29] Allen, L and Pantzalis, C. (1996) Valuation of the Operating Flexibility of Multinational Corporations. Journal of International Business Studies, 27, 633-653. https://doi.org/10.1057/palgrave.jibs.8490147

[30] Pigou, A. (1920) The Economics of Welfare. MacMillan and Co., London.

[31] Coase, R.H. (1960) The Problem of Social Cost. In: Gopalakrishnan, C., Ed., Classic Papers in Natural Resource Economics, Palgrave Macmillan, London, 87-137. https://doi.org/10.1057/9780230523210 6

[32] Baker, T., et al. (2007) Carbon Leakage. In: Mitigation from Cross-Sectoral Perspectives; Climate Change, Cambridge University Press, Cambridge, UK and New York.

[33] Gupta, S., et al. (2007) Taxes and Charges: Policies, Instruments and Co-Operative Arrangements. Climate Change. Cambridge University Press, Cambridge, UK and New York.

[34] Merton, R.C. (1897) An Intertemporal Capital Assdet Pricing Model. Econometrica, 41, 867-887. https://doi.org/10.2307/1913811

[35] Weitzman, M.L. (2007) A Review of the Stern Review on the Economics of Climate Change. Journal of Economic Literature, 45, 703-724. https://doi.org/10.1257/jel.45.3.703

[36] Insley, M. (2002) A Real Options Approach to the Valuation of a Forestry Investment. Journal of Environmental Economics and Management, 44, 471-492. https://doi.org/10.1006/jeem.2001.1209

[37] Zvan, R., Forsyth, P.A. and Vetzal, K.R. (1998) Penalty Methods for American Options with Stochastic Volatility. Journal of Computational and Applied Mathemat- 
ics, 91, 199-218. https://doi.org/10.1016/S0377-0427(98)00037-5

[38] Wilmott, P. (1998) Derivatives: The Theory and Practice of Financial Engineering. Wiley, New York.

[39] Reed, W.J. and Clarke, H.R. (1990) Harvest Decisions and Asset Valuation for Biological Resources Exhibiting Size-Dependent Stochastic Growth. International Economic Review, 31, 147-169. https://doi.org/10.2307/2526634

[40] Cox, J.C., Ross, S.A. and Rubinstein, M. (1979) Option Pricing: A Simplified Approach. Journal of Financial Economics, 7, 229-263.

https://doi.org/10.1016/0304-405X(79)90015-1 


\section{Appendix}

Table 1 is a table of expected values at various levels of cash flows (in thousands) against different carbon tax rates. We find that when the amount of cash flow expected from an investment is at $\$ 5000$ and above, the value of the investment decreases as the rate of carbon tax increases. The result also suggests the value on an investment is not significantly impacted by carbon taxes when cash flows are at $\$ 2500$ or zero. Following Table 1 is Figure 1 depicting the graphical relationship between expected values, cash flows and carbon tax rates.

Table 1. Expected value, cash flow and carbon tax rate $(\tau / \pi)$ (unit of cash flow in '000s).

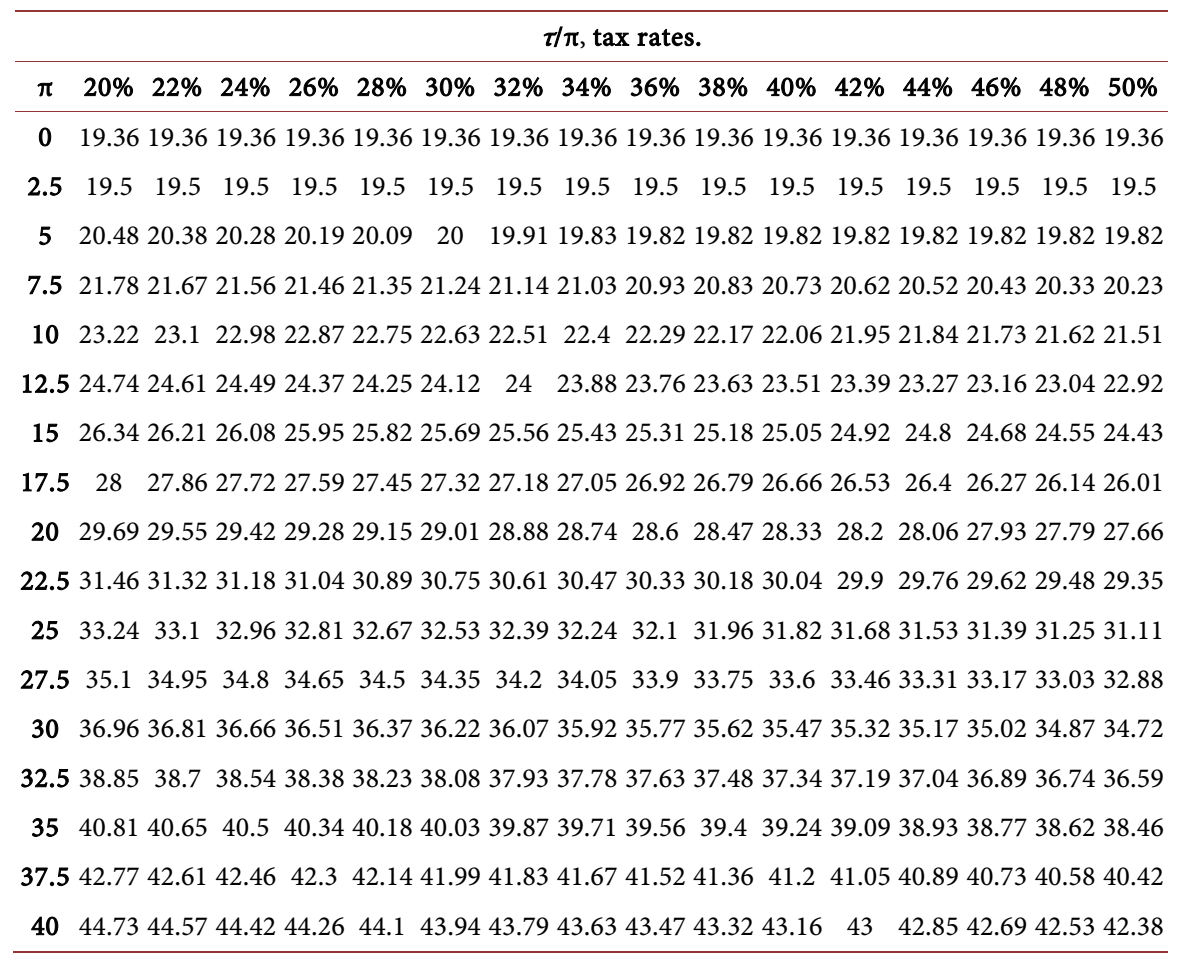

Basic model. $\pi=10 k, \frac{\tau}{\pi}=20 \%, \mathrm{~d} \pi=0.01 \mathrm{~d} t+0.13 \mathrm{~d} z, K(t)=50 \exp (-0.5 t), \delta=5 \%, T=25$.

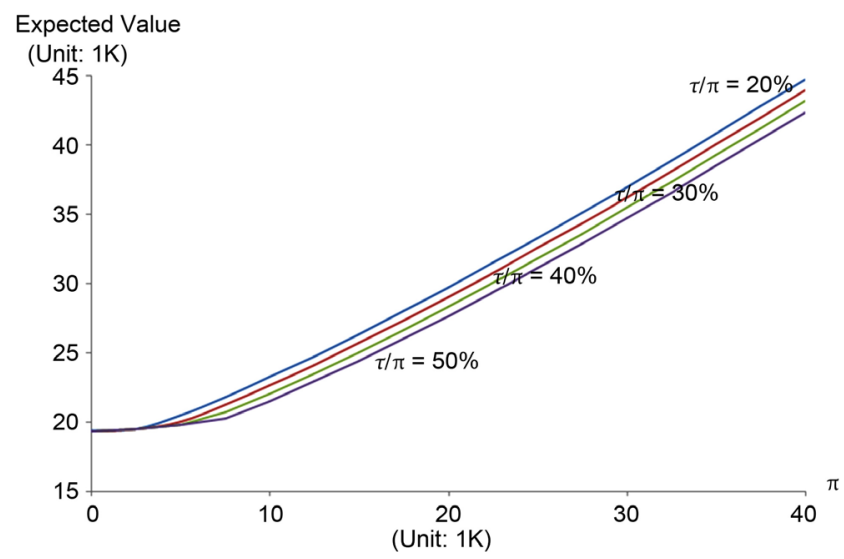

Figure 1. Figure 1 of Table 1: Expected value, cash flows and carbon tax rate. 
Table 2 and related Figure 2 show how expected value changes as the drift rate changes from 0.01 to 0.30 . The results indicate that increasing the drift rate, (which is the change in the average value of the stochastic cash flow) will increase the expected value of the investment across all carbon tax rates. Intuitively, if the carbon tax rate is fixed, increasing the drift rate will increase value of the investment. The results are similar when we analyzed how the value of investment will be affected by changing the volatility of the cash flow. The average rate of change in the investment value is about $0.4 \%$ for both the drift rate and volatility.

Table 2. Expected Value, Carbon tax rate and Drift $\alpha$ (units: $1 \mathrm{k}$ ).

\begin{tabular}{|c|c|c|c|c|}
\hline \multirow[b]{2}{*}{$\tau / \pi$} & \multicolumn{4}{|c|}{$a$} \\
\hline & 0.01 & 0.10 & 0.20 & 0.30 \\
\hline $20 \%$ & 23.22 & 23.22 & 23.22 & 23.31 \\
\hline $22 \%$ & 23.10 & 23.14 & 23.19 & 23.19 \\
\hline $24 \%$ & 22.98 & 23.02 & 23.07 & 23.08 \\
\hline $26 \%$ & 22.87 & 22.91 & 22.96 & 22.96 \\
\hline $28 \%$ & 22.75 & 22.79 & 22.84 & 22.84 \\
\hline $30 \%$ & 22.63 & 22.67 & 22.72 & 22.73 \\
\hline $32 \%$ & 22.51 & 22.56 & 22.60 & 22.61 \\
\hline $34 \%$ & 22.40 & 22.44 & 22.49 & 22.49 \\
\hline $36 \%$ & 22.29 & 22.33 & 22.38 & 22.38 \\
\hline $38 \%$ & 22.17 & 22.22 & 22.27 & 22.27 \\
\hline $40 \%$ & 22.06 & 22.11 & 22.16 & 22.16 \\
\hline $42 \%$ & 21.95 & 22.00 & 22.05 & 22.05 \\
\hline $44 \%$ & 21.84 & 21.88 & 21.93 & 21.94 \\
\hline $46 \%$ & 21.73 & 21.77 & 21.82 & 21.83 \\
\hline $48 \%$ & 21.62 & 21.66 & 21.71 & 21.72 \\
\hline $50 \%$ & 21.51 & 21.55 & 21.61 & 21.61 \\
\hline
\end{tabular}

Basic Model: $\quad \pi=10 k, \frac{\tau}{\pi}=20 \%, \mathrm{~d} \pi=0.01 \mathrm{~d} t+0.13 \mathrm{~d} z, K(t)=50 \exp (-0.5 t), \delta=5 \%, T=25$.

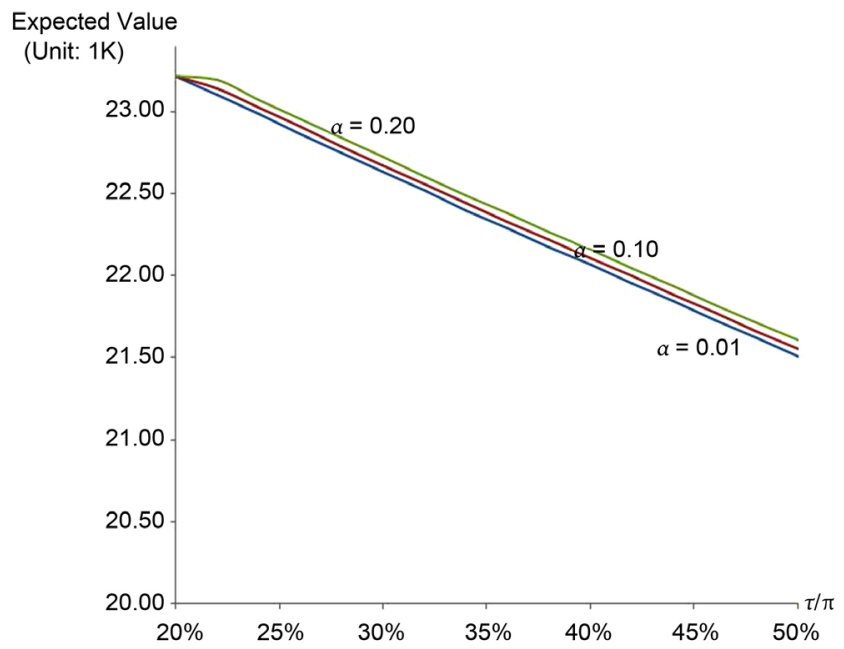

Figure 2. Figure 2 of Table 2: Expected value, carbon tax rate and drift. 
Table 3. Expected value, carbon tax rate and volatility $\sigma$ (units: $1 \mathrm{k}$ ).

\begin{tabular}{|c|c|c|c|c|c|}
\hline & & & $\sigma$ & & \\
\hline$\tau / \pi$ & 0.13 & 0.53 & 1.03 & 1.53 & 2.03 \\
\hline $20 \%$ & 23.22 & 23.23 & 23.25 & 23.27 & 23.30 \\
\hline $22 \%$ & 23.10 & 23.12 & 23.13 & 23.15 & 23.19 \\
\hline $24 \%$ & 22.98 & 23.00 & 23.02 & 23.03 & 23.07 \\
\hline $26 \%$ & 22.87 & 22.88 & 22.90 & 22.92 & 22.95 \\
\hline $28 \%$ & 22.75 & 22.77 & 22.78 & 22.80 & 22.84 \\
\hline $30 \%$ & 22.63 & 22.65 & 22.67 & 22.68 & 22.72 \\
\hline $32 \%$ & 22.51 & 22.53 & 22.55 & 22.57 & 22.60 \\
\hline $34 \%$ & 22.40 & 22.42 & 22.44 & 22.45 & 22.49 \\
\hline $36 \%$ & 22.29 & 22.30 & 22.32 & 22.34 & 22.38 \\
\hline $38 \%$ & 22.17 & 22.19 & 22.21 & 22.23 & 22.27 \\
\hline $40 \%$ & 22.06 & 22.08 & 22.10 & 22.12 & 22.15 \\
\hline $42 \%$ & 21.95 & 21.97 & 21.99 & 22.01 & 22.04 \\
\hline $44 \%$ & 21.84 & 21.86 & 21.88 & 21.89 & 21.93 \\
\hline $46 \%$ & 21.73 & 21.75 & 21.77 & 21.78 & 21.82 \\
\hline $48 \%$ & 21.62 & 21.64 & 21.66 & 21.67 & 21.71 \\
\hline $50 \%$ & 21.51 & 21.53 & 21.55 & 21.57 & 21.60 \\
\hline
\end{tabular}

Basic Model: $\pi=10 k, \frac{\tau}{\pi}=20 \%, \mathrm{~d} \pi=0.01 \mathrm{~d} t+0.13 \mathrm{~d} z, K(t)=50 \exp (-0.5 t), \delta=5 \%, T=25$.

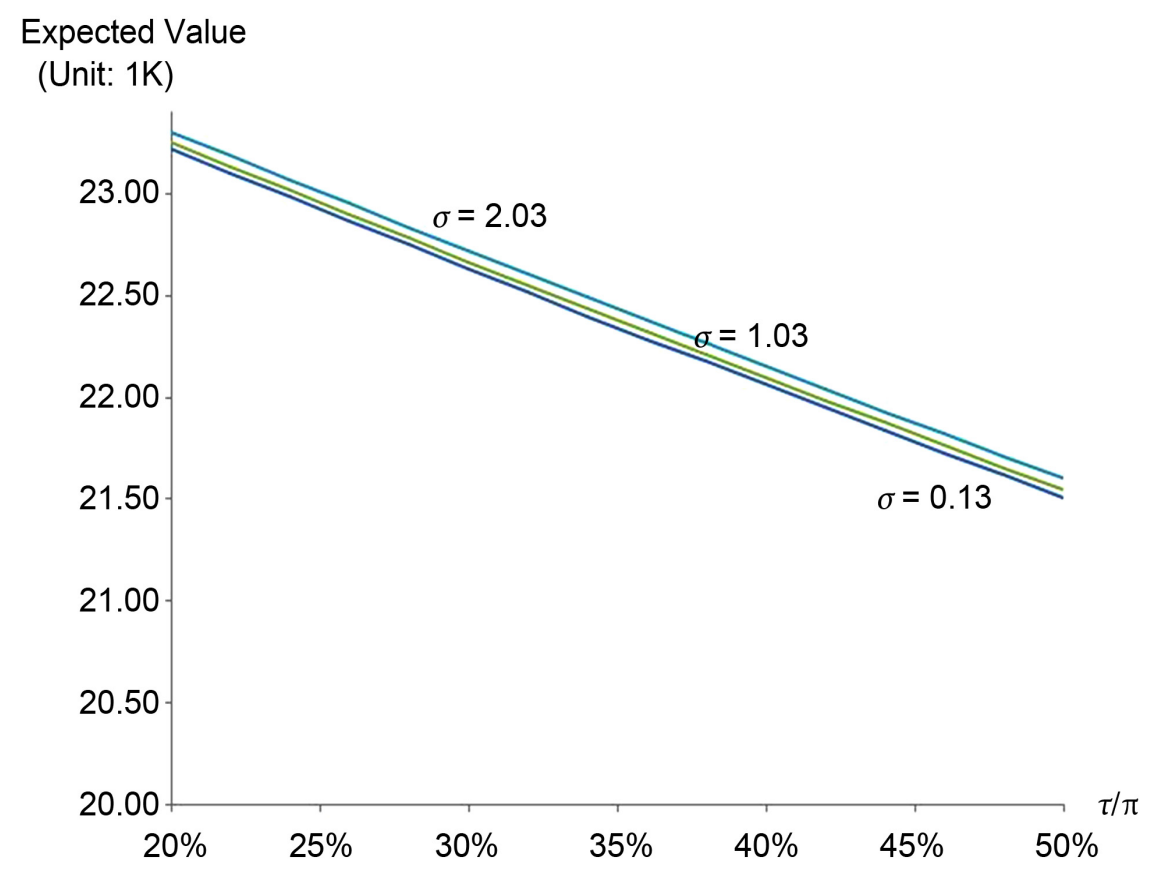

Figure 3. Figure 3 of Table 3: Expected value, carbon tax rate and volatility. 
Next is the analysis on how adopting a new technology will impact the value of the investment. Interestingly the result shows that the adoption of new of technology (increasing from an arbitrary low value of 20 to a higher value of 50, a better technology) almost doubles the value of the investment regardless the rate of carbon tax. By deduction, the effect of carbon tax is mitigated given the level of efficiency of the technology adopted to minimize carbon emissions. Table 4 and Figure 4 illustrate.

Table 4. Expected value, carbon tax rate and technology $K$ (units: $1 \mathrm{k}$ ).

\begin{tabular}{|c|c|c|c|c|c|c|c|}
\hline & & & & $K$ & & & \\
\hline$\tau / \pi$ & 20 & 25 & 30 & 35 & 40 & 45 & 50 \\
\hline $20 \%$ & 12.40 & 14.13 & 15.90 & 17.70 & 19.53 & 21.36 & 23.22 \\
\hline $22 \%$ & 12.26 & 13.99 & 15.77 & 17.57 & 19.40 & 21.24 & 23.10 \\
\hline $24 \%$ & 12.11 & 13.86 & 15.64 & 17.44 & 19.28 & 21.12 & 22.98 \\
\hline $26 \%$ & 11.97 & 13.72 & 15.51 & 17.32 & 19.16 & 21.00 & 22.87 \\
\hline $28 \%$ & 11.83 & 13.59 & 15.38 & 17.20 & 19.04 & 20.89 & 22.75 \\
\hline $30 \%$ & 11.69 & 13.45 & 15.25 & 17.07 & 18.91 & 20.77 & 22.63 \\
\hline $32 \%$ & 11.56 & 13.32 & 15.12 & 16.95 & 18.79 & 20.65 & 22.51 \\
\hline $34 \%$ & 11.42 & 13.19 & 14.99 & 16.83 & 18.67 & 20.53 & 22.40 \\
\hline $36 \%$ & 11.29 & 13.06 & 14.87 & 16.71 & 18.55 & 20.42 & 22.29 \\
\hline $38 \%$ & 11.15 & 12.93 & 14.74 & 16.58 & 18.44 & 20.30 & 22.17 \\
\hline $40 \%$ & 11.01 & 12.80 & 14.62 & 16.46 & 18.32 & 20.18 & 22.06 \\
\hline $42 \%$ & 10.88 & 12.67 & 14.50 & 16.34 & 18.20 & 20.07 & 21.95 \\
\hline $44 \%$ & 10.74 & 12.54 & 14.38 & 16.22 & 18.09 & 19.96 & 21.84 \\
\hline $46 \%$ & 10.61 & 12.42 & 14.25 & 16.11 & 17.97 & 19.85 & 21.73 \\
\hline $48 \%$ & 10.48 & 12.29 & 14.13 & 15.99 & 17.85 & 19.74 & 21.62 \\
\hline $50 \%$ & 10.35 & 12.17 & 14.01 & 15.87 & 17.74 & 19.62 & 21.51 \\
\hline
\end{tabular}

Basic Model: $\pi=10 k, \frac{\tau}{\pi}=20 \%, \mathrm{~d} \pi=0.01 \mathrm{~d} t+0.13 \mathrm{~d} z, K(t)=50 \exp (-0.5 t), \delta=5 \%, T=25$.

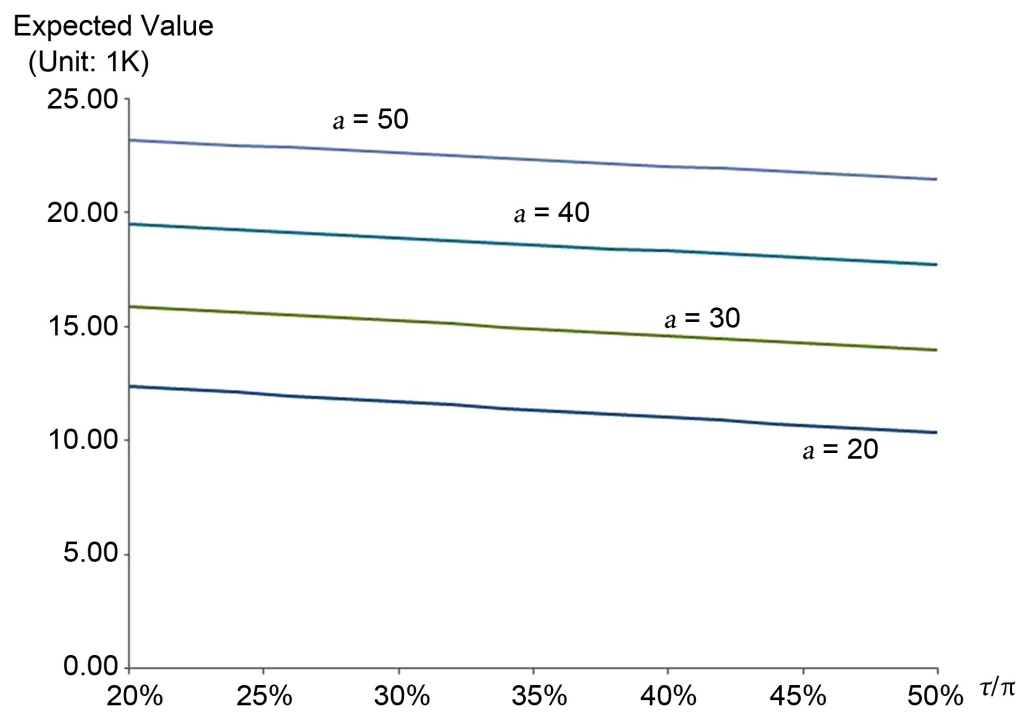

Figure 4. Figure 4 of Table 4: Expected value, carbon tax rate and technology. 
Following the results of how the adoption of a new technology could mitigate the effect of carbon taxes on the value of an investment is the speed at which the adopted technology could become more relevant or obsolete over time. This is referred to as $b$ in our model. The value of an investment is negatively impacted if the effect of technology decays over time and the adopted technology becomes less effective in ameliorating the level of carbon emissions. Table 5 and Figure 5 show the speed at which the value of an investment could decline over time as the effect of technology declines with time.

Table 5. Expected value, new tech function $K(t)=K * \exp (-b t)$ and its effect over time (units: $1 \mathrm{k}$ ).

\begin{tabular}{|c|c|c|c|c|c|c|c|}
\hline \multirow[b]{2}{*}{$b$} & \multicolumn{7}{|c|}{$K$} \\
\hline & 20 & 25 & 30 & 35 & 40 & 45 & 50 \\
\hline 0 & 38.97 & 48.55 & 58.14 & 67.72 & 77.31 & 86.89 & 96.48 \\
\hline 0.1 & 22.03 & 27.26 & 32.49 & 37.73 & 42.96 & 48.19 & 53.42 \\
\hline 0.2 & 16.69 & 20.07 & 23.51 & 26.98 & 30.49 & 34.01 & 37.55 \\
\hline 0.3 & 14.43 & 16.96 & 19.55 & 22.17 & 24.82 & 27.49 & 30.17 \\
\hline 0.4 & 13.18 & 15.23 & 17.32 & 19.44 & 21.60 & 23.77 & 25.95 \\
\hline 0.5 & 12.40 & 14.13 & 15.90 & 17.70 & 19.53 & 21.36 & 23.22 \\
\hline 0.6 & 11.86 & 13.36 & 14.91 & 16.49 & 18.08 & 19.69 & 21.32 \\
\hline 0.7 & 11.46 & 12.81 & 14.19 & 15.60 & 17.03 & 18.46 & 19.91 \\
\hline 0.8 & 11.15 & 12.39 & 13.64 & 14.93 & 16.22 & 17.52 & 18.84 \\
\hline
\end{tabular}

Basic Model: $\pi=10 k, \frac{\tau}{\pi}=20 \%, \mathrm{~d} \pi=0.01 \mathrm{~d} t+0.13 \mathrm{~d} z, K(t)=50 \exp (-0.5 t), \delta=5 \%, T=25$.

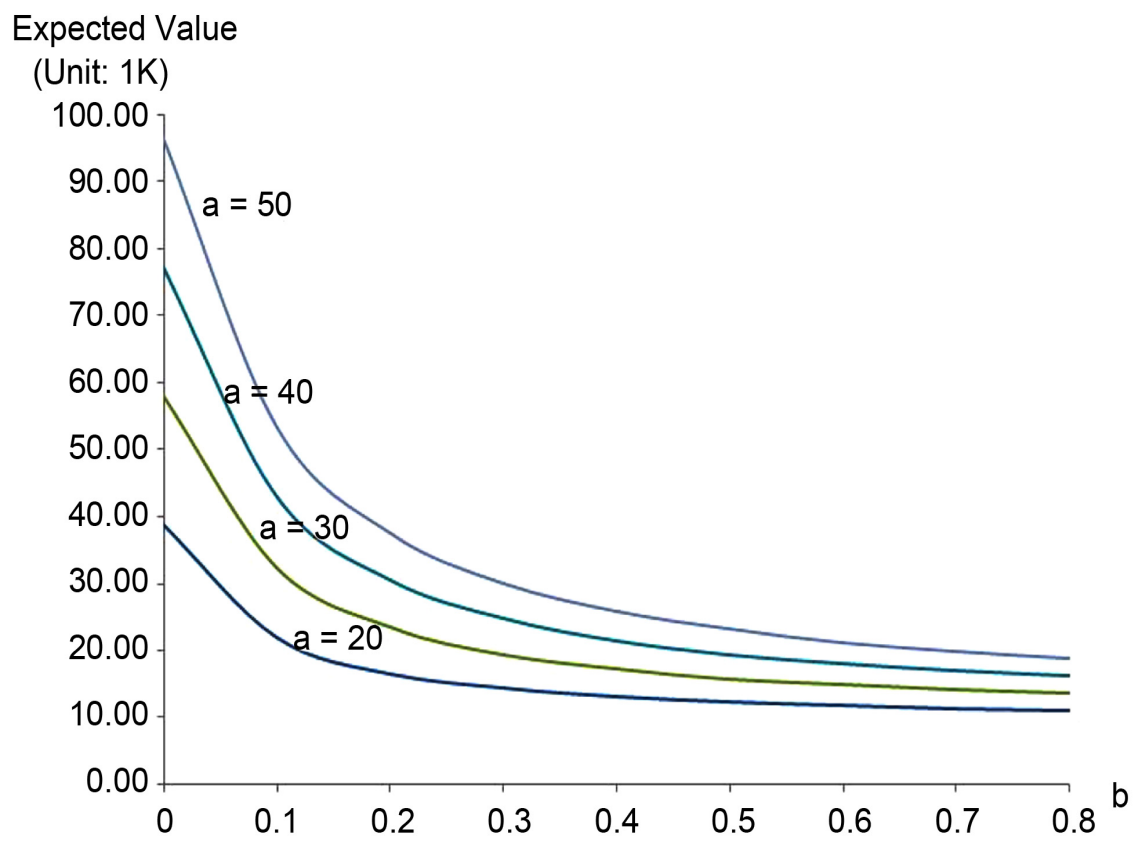

Figure 5. Figure 5 of Table 5. 
Conversely, the results are dramatically reversed if the effect of technology on carbon emissions and carbon taxes becomes even more effective.

Table 6. Expected value, new tech with $K(t)=50 \exp ( \pm b t)$ changing over time (units: 1 $\mathrm{k})$.

\begin{tabular}{ccc}
\hline $\boldsymbol{b}$ & $K(t)=50 \exp (-b t)$ & $K(t)=50 \exp (b t)$ \\
\hline $\mathbf{0}$ & 96.48 & 96.48 \\
$\mathbf{0 . 1}$ & 53.42 & 262.87 \\
$\mathbf{0 . 2}$ & 37.55 & 1201.11 \\
$\mathbf{0 . 3}$ & 30.17 & 8143.04 \\
$\mathbf{0 . 4}$ & 25.95 & $>10 \mathrm{~K}$ \\
$\mathbf{0 . 5}$ & 23.22 & $>10 \mathrm{~K}$ \\
$\mathbf{0 . 6}$ & 21.32 & $>10 \mathrm{~K}$ \\
$\mathbf{0 . 7}$ & 19.91 & $>10 \mathrm{~K}$ \\
$\mathbf{0 . 8}$ & 18.84 & $>10 \mathrm{~K}$ \\
\hline
\end{tabular}

Basic Model: $\pi=10 k, \frac{\tau}{\pi}=20 \%, \mathrm{~d} \pi=0.01 \mathrm{~d} t+0.13 \mathrm{~d} z, K(t)=50 \exp (-0.5 t), \delta=5 \%, T=25$.

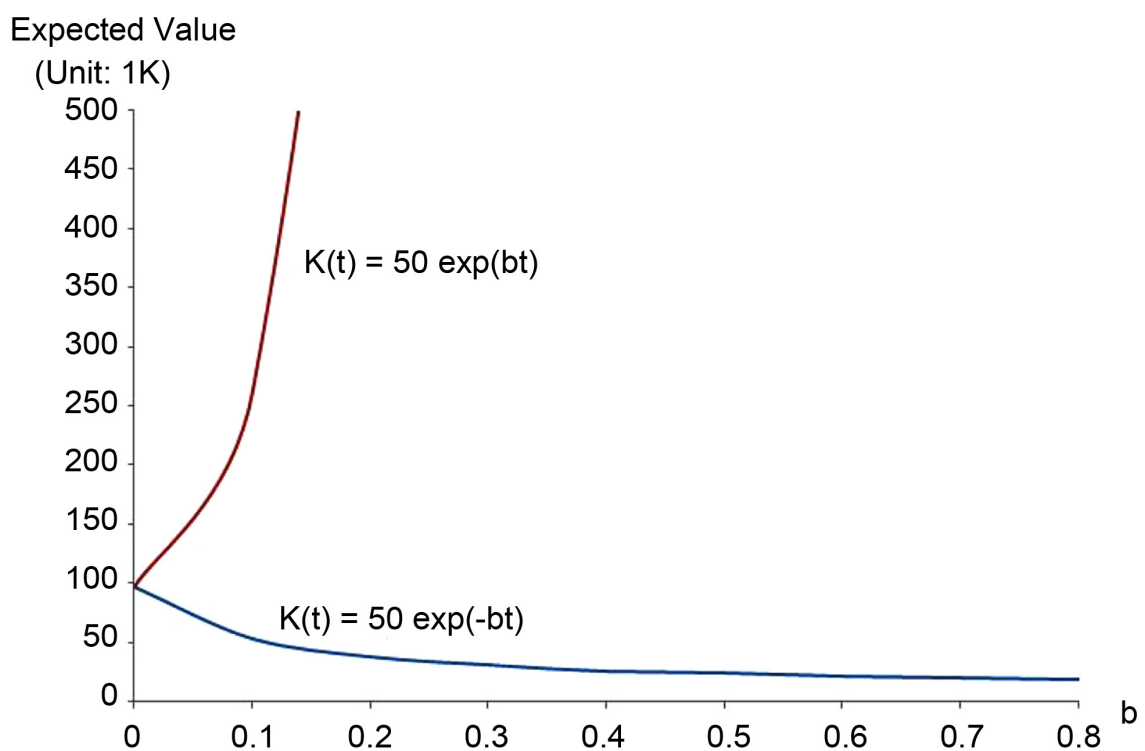

Figure 6. Figure 6 of Table 6.

The expected value of an investment involves discounting the expected after tax cash flows using the appropriate discount rate. While the choice of the appropriate discount is central to finance and investment analysis, the problem of analyzing the effect of discount rates on the expected values of long term irreversible investments is exacerbated due to the high degree of uncertainty about appropriate discount rate. For simplicity, this paper iteratively modeled how the expected value of an investment will change given different discount rate regimes. As expected, the lower the discount rate the higher the expected value of the investment over time. See Table 7 and Figure 7. 
Table 7. Expected value, discount rate and time horizon (units: $1 \mathrm{k}$ ).

\begin{tabular}{ccccccc}
\hline & & \multicolumn{5}{c}{$T$} \\
\hline $\boldsymbol{\delta}$ & $\mathbf{2 0}$ & $\mathbf{2 1}$ & $\mathbf{2 2}$ & $\mathbf{2 3}$ & $\mathbf{2 4}$ & $\mathbf{2 5}$ \\
\hline $\mathbf{1 \%}$ & 8.87 & 9.86 & 11.62 & 14.62 & 19.68 & \\
$\mathbf{2 \%}$ & 8.48 & 9.32 & 10.90 & 13.70 & 18.49 & \\
$\mathbf{3 \%}$ & 8.24 & 8.93 & 10.35 & 12.96 & 17.52 & \\
$\mathbf{4 \%}$ & 8.09 & 8.64 & 9.91 & 12.36 & 16.71 & \\
$\mathbf{6 \%}$ & 8.02 & 8.42 & 9.56 & 11.85 & 16.01 & \\
$\mathbf{7 \%}$ & 8.00 & 8.27 & 9.27 & 11.42 & 15.41 & \\
$\mathbf{8 \%}$ & 8.00 & 8.14 & 9.01 & 11.03 & 14.85 & \\
$\mathbf{9 \%}$ & 8.00 & 8.07 & 8.82 & 10.70 & 14.38 & \\
$\mathbf{1 0 \%}$ & 8.00 & 8.00 & 8.63 & 10.39 & 13.93 & \\
\hline & 8.00 & 8.00 & 8.49 & 10.14 & 13.54 &
\end{tabular}

Basic Model: $\pi=10 k, \frac{\tau}{\pi}=20 \%, \mathrm{~d} \pi=0.01 \mathrm{~d} t+0.13 \mathrm{~d} z, K(t)=50 \exp (-0.5 t), \delta=5 \%, T=25$.

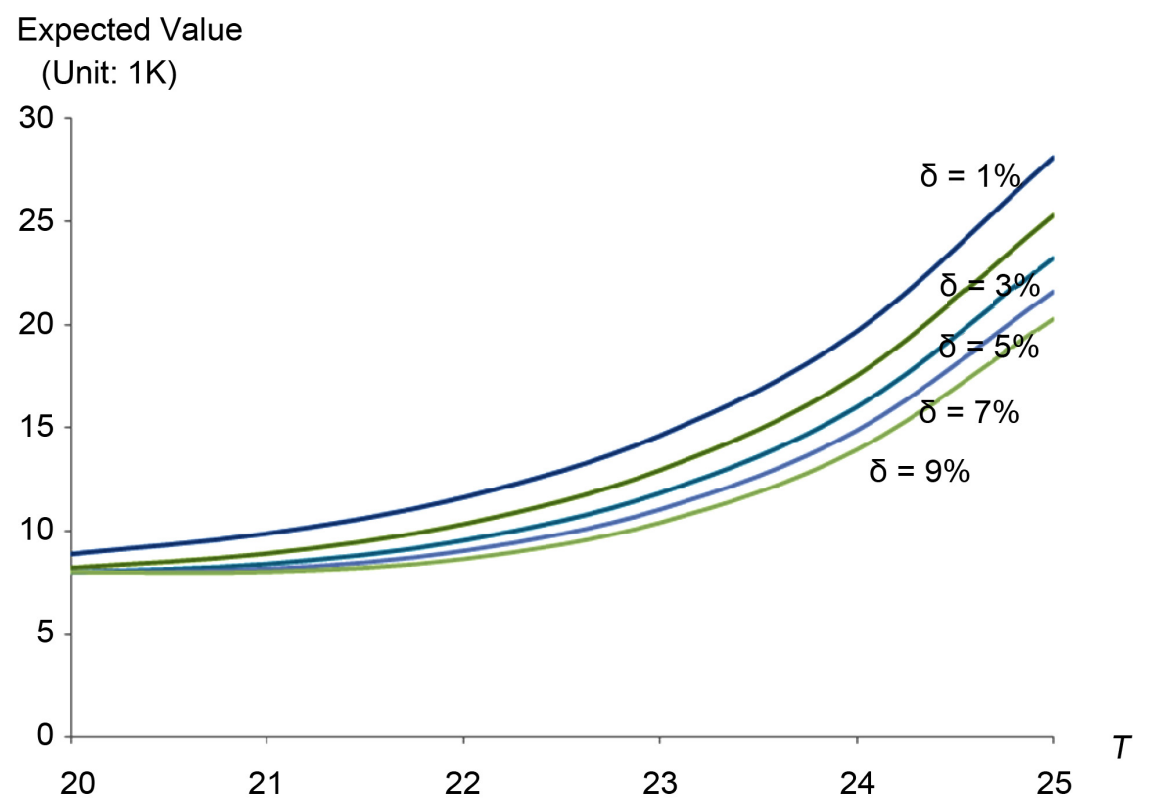

Figure 7. Figure 7 of Table 7. 